\title{
Analyzing the Differentiation Strategies Of Big Companies Competing With Each Other
}

\author{
$\mathrm{Ze} \mathrm{Ye}$ \\ Changsha University of Science and Technology, School of Economics \& Management, Hunan, China \\ Hassan Abbas \\ Changsha University of Science and Technology, School of Economics \& Management, Hunan, China
}

\section{Talib Hussain}

School of Media and communication, Shanghai Jiao Tong University, 800, Dongchuan Road, Minhnag District, 200240, Shanghai, China

\section{Jiao He}

Changsha University of Science and Technology, School of Economics \& Management, Hunan, China

\begin{abstract}
The purpose of the research was to evaluate the competitive strategies of the two big companies in Pakistan. To achieve this aim, the two competing companies in the ice cream sector were evaluated that include Unilever Pakistan and Engro for their brands Magnum and Omore respectively. The primary research was conducted using a questionnaire survey as the research instrument. The instrument was evaluated for its reliability and then the research was conducted with 100 consumers. The findings were relevant to the literature discussed in the research that the product is differentiated by adding value to add. Additionally, it was also found that to create value it is not limited to add value through quality, but it can also be differentiated by adding features into the product to add value. Nevertheless, the findings from the study revealed that the consumers in Pakistan prefer the differentiated product. Particularly, the consumers preferred Magnum ice cream over Cornetto and Omore because it was rich in taste and quality. Although, consumers also regarded it as expensive but they also responded to a survey that it offers value for the price. Notably, the consumers were also found preferring a low-cost product which indicates that in Pakistan the competitive strategy that is successful is differentiation and that Unilever Pakistan capitalizes with differentiation through Magnum and also serves lowcost markets and competes with OMORE brand. The recommendations were proposed for further research.
\end{abstract}

\section{Keywords}

Differentiation Strategies, Big Companies of Pakistan, Ice cream sector, Unilever Pakistan, Engro Foods, LowCost Leadership, Analyzing Differentiation Strategy.

\section{Introduction}

In today's competitive business environment, everything for everyone is no longer applicable to create differentiation among the customers. The customers today have become more aware, and they have a deeper knowledge of the products, and they also consider pricing factor apart from the differentiation for purchase (Davcik \& Sharma, 2015). Nevertheless, being different is not enough to create differentiation rather it re- quires adding value to the product to ensure the differentiation. Adding value means helping clients solve problems they could not solve without the support of a particular company, or take advantage of opportunities that were previously not available to them. In this essence, the studies have been conducted to determine the need of differentiated products in particular industry for instance retail, fashion, tourism, banking and FMCG industry (Rungtrakulchai, 2018; Sharma \& Sharma, 2017) 
Nevertheless, the experts emphasize particularly for the commodities industry to ensure differentiation because those products that do not vary from one place to another, do not exist since each company offers them in a different way, adapted to the needs of its customers, which are all different (Hudson, Huang, Roth \& Madden, 2016; Walsh, Shiu \& Hassan, 2014). In this spirit, it is essential for the companies in the contemporary business environment to be very competitive (Anđelković \& Radosavljević; Zdraveski, Janeska $\&$ Taleska, 2014), just like that will be able to establish themselves in the current markets where there is a great competitive rivalry between the companies. This is how one of the main decisions that must be made by the business owners when establishing an organization or company, it is the choice of the business strategy to follow. Among the competitor strategies of Porter; two of the most utilized strategies are differentiation and low-cost leadership where most of the companies compete (D. Banker, Mashruwala \& Tripathy, 2014; Gallopel-Morvan, Gabriel, Le Gall-Ely, Rieunier \& Urien, 2013). Correspondingly, the current research would explore the differentiation strategies of two big companies in the commodity industry of Pakistan that compete with each other.

\subsection{Problem statement}

Most of the companies in the contemporary business environment compete on the basis of differentiation and low-cost leadership strategy as their competitive strategies. The recent research in the academic literature is conducted to determine the need of the differentiated products in Western market (Kilian \& Hennigs, 2014; Koulayev, 2014), whereas in the context of Pakistan the study on competitive strategies is performed in the textile industry (Afridi, Saboor, Tariq \& Ishaq, 2016; Loken et al., 2011). However, the other industries like commodities and FMCG have been overlooked to determine their competitive strategies (Farkas, 2016). Since differentiation plays a vital role in the business development and marketing by offering the customers enough incentives to choose a particular company instead of the competitor's or substitute; thus, it is essential to determine the need of differentiation and how the companies compete to create differentiation. Therefore, the problem that the current research aims to analyze how the big companies in Pakistan compete and what differentiation strategy they use to compete with each other.

\subsection{Research Aims and Objectives}

The aim of the research is to analyze the differentiation strategies that the Pakistani companies use to compete with each other where the undertaken organizations are Unilever Pakistan and Engro Corporation. Particularly, the companies compete in the frozen dessert and ice cream sector where Unilever Pakistan has walls and Magnum and Engro Corporation competes with Omore as its ice cream and frozen dessert brand under Engro Foods. The present research would analyze how the companies compete by implementing differentiating in the frozen dessert product. Following are the research objectives that the research would address:

- to determine the impact of consumer's decision towards the differentiated product in the frozen dessert category.

- to analyze the impact of consumer's decision towards the low-priced product in the frozen dessert category.

- to evaluate the successfulness of differentiation strategies implemented by Engro and Unilever Pakistan.

\section{Literature review}

\subsection{Concept of competitive strategies}

Competitive strategy is defined by Porter and Lee (Lewis \& Ling, 2015; Porter \& Lee, 2015) as a strategy that involves an offensive or defensive action to create a defensible position against the five forces competitive markets, in such a way that a result is above the average of the company's competitors of the industrial sector. The strategic competitiveness involves positioning a business to maximize the value of the capabilities that distinguish it from its competitors, at the same time the goal of any generic strategy is "to create value for buyers" (Grant, 2016). The competitive strategy is aimed to search for a favorable competitive position in a sector industrial. The competitive strategy is about establishing a profitable and sustainable position against the forces that determine the competition in the industrial sector. In this context, Liu \& Atuahene-Gima, (2018) and Gellweiler, (2018); Salavou, (2015) agree that the main interest of these generic strategies is aspects of the competition, such as the creation of distinctive advantages. Similarly, for Porter and Heppelmann (Gilmore, Tavakoly, Taylor \& Reed, 2013; Porter \& Heppelmann, 2015), the strategy chosen by the company is an activity that adds 
value in the product; therefore, the underlying idea is to look for a strategy that favors the maintenance of the comparative advantage for the company.

In this sense, competitive actions are defined as competing movements initiated by a company externally addressed to increase its relative competitive position. According to Armstrong, Kotler, Harker \& Brennan, (2015), this strategy is not only implemented to add value to a product but also the value can be added to the features of the product including the segmentation and availability of the product in markets. The similar argument has been made by Rothaermel, (2015), who argues that the companies create differentiation apart from creating value in the product by increasing the features of the product like complimentary services that are different from the competitor's product. The argument is also consistent with Armstrong, Kotler, Harker, and Brennan (Armstrong et al., 2015; Hoek \& Robertson, 2015) who argues that the objective of the competitive strategy is to understand the roads through of which companies compete with each other. The strategy would be the tool to improve the competitiveness of companies. Nevertheless, Block, Kohn, Miller, and Ullrich (Block, Kohn, Miller \& Ullrich, 2015) argues that it requires the company resources to create differentiation because a competitive strategy requires company efforts and resources.

\subsection{Types of competitive strategies}

According to Porter and Heppelmann (Porter \& Heppelmann, 2015), the companies can achieve competitive advantage in four different ways where the first is differentiation that is implemented by adding value for the customer. The second is cost-leadership, where the brand competes due to the low price and the third is focus strategy where the company serves a narrow market segment that has been overlooked by most of the companies (Hansen, Nybakk \& Panwar, 2015; Hsu, Myers, Ribisl \& Marteau, 2013). The focus strategy has two variants that are cost focus and differentiation focus where the company has to ensure whether it would operate in a narrow market with cost leadership or differentiation. Each of generic strategies involves a fundamental route for achieving competitive advantage by selecting a strategy to achieve its strategic objective that is achieved through competitive advantage (Beglari, 2017; Ford, Moodie \& Hastings, 2012). Although choosing and implementing a generic strategy is far from simple, but the companies decide to choose a particular strategy based on the market and considering the competitor's strategy.

Nevertheless, there are also companies that perform without the competitive advantage which Porter identified as be everything to everyone recipe for strategic mediocrity and performance below average a company has no competitive advantage at all (Laari, Töyli \& Ojala, 2017). The concept of generic strategy Porter is based on the premise that there several ways to achieve competitive advantage depending on the structure of the sector industrial. If all companies in an industrial sector followed the same principles of competitive strategy, there would also be no competitive advantage. In this context, authors Brenes, Montoya \& Ciravegna, (2014); Cherrier \& Gurrieri (2014) also agree and further argues that in such a case it requires the companies to focus on bringing differentiation to become prominent among consumers. Besides, there is VRIO framework that is focused on the principle that the companies can differentiate if they have the ability to become valuable, rare, difficult to imitate and have the ability to exploit the resources and capabilities (Stead et al., 2013; Tan \& Sousa, 2015). Realizing the latter framework is difficult, but it ensures the sustainable competitive advantage for the companies.

\subsection{Successfulness of differentiation strategy}

Regarding the differentiation strategy, it has been argued by Manev, Manolova, Harkins \& Gyoshev, (2015) that the basic factors that the company needs to contribute to creating differentiation are in the form of research and development, marketing, production and other key dimensions. The researchers also claim that to become different from the competitors, it requires creating value for the customers and also investing integrative efforts of the companies to achieve differentiation (D. Banker et al., 2014). In contrast, there are researchers who agree with the fact that the differentiation can be achieved through the additional features and complimentary services, but it does not require additional resources. Particularly, it has been found in the study conducted by researchers Gabrielsson, Seppälä \& Gabrielsson, (2016); McAuley, (2014) who revealed that there are companies who have added value in the services for their core products to create differentiation. In this context, researchers Mathooko \& Ogutu (2015); Sacks et al., (2015) argue that the 
key to differentiation is understanding the company, customers, and all the stakeholders and create value to ensure the business success.

It is clear that each company has its particularities and therefore there would not be two equal strategies since each company has different objectives, available resources, capabilities, different areas and scope (Arli, Rundle-Thiele \& Lasmono, 2015; Oyewobi, Windapo \& James, 2015). However, the companies that have similar strategies share similar products and have a similar story, but they also compete to develop new resources and capabilities. Similarly, companies whose strategies are markedly different will also tend to be markedly different with respect to their resources (Kim, Shin \& Min, 2016); a match is not necessarily absolute among the strategies. In this context, Porter \& Heppelmann (2015) argue that a company gets competitive advantages when it gets to perform activities strategically relevant, to understand the variation in costs and sources potential or existing differentiation. In other words, a company gets competitive advantages when it gets to perform these strategically important activities better or more cheaply than their competitors (Lechner \& Gudmundsson, 2014). Each of the activities can be a source of competitive advantage, alone or in combination with other activities, hence also the importance of the links between activities.

\section{Research methodology}

\subsection{Research design}

The research design is a general strategy of the research that defines how the data would be collected and analyzed for the study. There are a number of research designs available to a researcher which it can select where every design serves a different purpose. These research designs include the exploratory, meta-analysis, descriptive, mixed methods, case study and experimental research designs (Schmidt \& Hunter, 2014). As far as the current study is concerned, that is, to explore the differentiation of big companies in a competitive market in Pakistani context; there are limited results as to what has been done so far. Therefore, the exploratory research design would be implemented. It is also supported by Brown $\&$ Fletcher (2017), who argue that an exploratory research design supports to explore the phenomenon that has not been explored in detail before. Correspondingly, for the current research, this type of research design would support the re- searcher to complete the research by exploring the facts that have never been discovered.

\subsection{Research methodology}

There are basically two research methods the quantitative and qualitative; the quantitative research deals with the objective resolution of the problem statement whereas the qualitative deals with the subjective evaluation (Henriksen, 2012; Taylor, Bogdan \& DeVault, 2015). Besides, the researcher can also use a mixed method approach by collecting data in both the forms. For the current study, the quantitative research is undertaken because it would enable the researcher to conduct the research directly from the customers and to determine whether they want differentiation in the product. The quantitative research would also determine the facts that are left unexplored in the context of Pakistan where it particularly evaluates whether the employees prefer differentiation over cost-leadership. It will also quantify if the differentiation strategies used by the companies are successful.

\subsection{Data collection}

As far as data collection is concerned, there are a number of research instruments that enable the researcher to collect a particular type of data. According to (Brown \& Fletcher, 2017) the best tools for collecting quantitative data include questionnaires, surveys, polls and online surveys whereas the qualitative data is gathered using interviews, observations and focus group discussions. For the current study, because it is quantitative in nature, therefore, the particular data collection method is questionnaire survey. The reason for using a questionnaire survey is that it collects data from the consumers regarding the research context and it is simple to design

\subsection{Questionnaire design}

With the quantitative method, the undertaken data collection tool is questionnaire survey. There are two types of questionnaires; the open-ended that collects the qualitative data, and the close-ended that collects the quantitative data (Greenland, 2013; Joshi, Kale, Chandel \& Pal, 2015). Since the current research is quantitative therefore the close-ended questionnaire would be used to collect data from the consumers. The questionnaire was designed using the Likert's scale questionnaire that has five options for a question ranging from strongly agree to strongly disagree 
(Hartley, 2014; Sparks, 2015). The questionnaire is comprised of 12 questions where first four questions cover first research question, and the latter four questions cover second research question, and the last four questions measure the decision-making behavior of the consumers towards purchasing a differentiated product or a low-priced product. The questionnaire is selfadministrative where the participants can fill it without the guidance and interruption of the researcher (Lee, Henriksen, Rose, Moreland-Russell \& Ribisl, 2015; Taylor et al., 2015). The designed questionnaire aimed to analyze the differentiation strategies of two big companies in Pakistan who compete with each other in the frozen dessert sector.

\subsection{Sample and sampling design}

The sample refers to the smaller proportion of the population that has all the characteristics of the population. It is also defined by Greenland, 2013; Voss, Zimmermann \& Zimmermann, 2016 that the sample includes a smaller group of the population that reflects all the features of the population and the researcher conducts the study on the undertaken sample. According to Corona, Saez \& Stoffel (2014) and Greenland (2016) sampling is done to conduct the study from a smaller group because it is complex and time-consuming to consider entire population for conducting the study. Therefore, the researcher conducts the research on a smaller group that represents the population. The researcher can use probability or nonprobability sampling technique for sampling. In the probability sampling, there is an equal chance of the population being selected to participate in the study (Lotterhos \& Whitlock, 2015). However, the non-probability sampling is performed for the researchers that should be performed on a selected population.

For the current research, the undertaken sampling technique is non-probability sampling and under this category, the convenience sampling would be used to collect data from the consumers. Particularly, the convenience sampling enables the researcher to collect data from the respondents who can contribute effectively in the study for the research context (Xie \& Lu, 2015). Similarly, the researcher would conduct the study from 100 consumers that are a sufficient sample to conduct the study to achieve the objectives of the research. Moreover, with the convenience sampling technique, the researcher would be able to approach the customers who are within the vicinity to understand their views. The research is aimed to be conducted from 100 consumers in one of the supermarkets in Karachi, Pakistan.

\subsubsection{Model for the study}

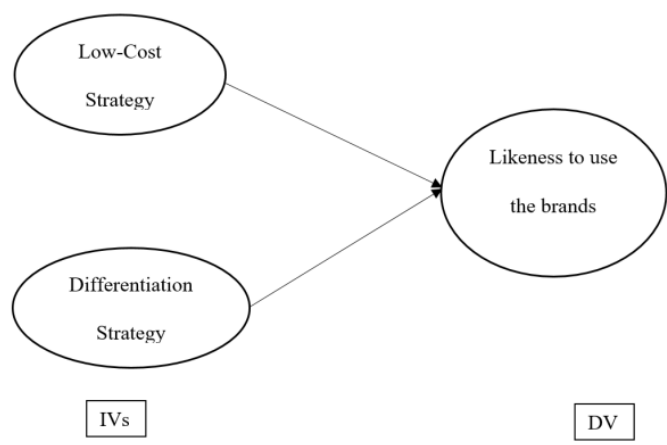

\subsection{Data analysis}

The analysis and presentation of data is an essential activity in the research because without interpreting the data the research cannot be concluded effectively. The analysis of the data takes place after the data has been collected by the researcher. Once, the data has been collected the researcher would evaluate it. Since, the present research is quantitative therefore the statistical analysis would be used (Huang, Liu \& Bowling, 2015). Particularly, the data collected through the Likert's scale questionnaire would be evaluated using SPSS where ANOVA tests would be conducted to determine the significance between the two variables that are consumer's decision making and differentiation strategy of the company offering frozen desserts.

\subsection{Reliability testing}

The reliability of the research instrument is measured to ensure that whether it measures consistently what it is supposed to measure. To measure the reliability there are different ways and statistical methods. However, the appropriate tool to measure the reliability of the current instrument is through is internal consistency reliability that measures how well the items in a test measure same construct (Heale \& Twycross, 2015). The internal consistency is denoted by alpha and the value of alpha closed to 1 is accepted for a reliable instrument. For the current research instrument that surveys instrument the reliability found is 0.762 (as illustrated in below Table 1 and 2) which indicates that it is a reliable instrument. 
Table 1 Case Processing Summary

\begin{tabular}{|c|c|c|c|}
\hline \multicolumn{2}{|c|}{} & $\mathrm{N}$ & $\%$ \\
\hline \multirow{3}{*}{ Cases } & Valid & 100 & 100.0 \\
\cline { 2 - 4 } & Excluded $^{\mathrm{a}}$ & 0 & .0 \\
\cline { 2 - 4 } & Total & 100 & 100.0 \\
\hline
\end{tabular}

a. Listwise deletion based on all variables in the procedure.

Table 2 Reliability Statistics

\begin{tabular}{|c|c|}
\hline Cronbach's Alpha & N of Items \\
\hline .762 & 12 \\
\hline
\end{tabular}

\subsection{Evaluating the questionnaire survey findings}

\section{Question 1}

The first question in the survey that was inquired from the customers was whether they find the Magnum ice cream brand as outstanding in comparison to the other brands available in the market. The results obtained on this question indicate that there were $27 \%$ of the respondents who strongly agreed and 53\% agreed whereas a significant proportion of $16 \%$ had neutral views whereas only $4 \%$ of the respondents have unfavorable views who disagreed with the state as shown in Chart 1. In sum, the overall findings were that about $80 \%$ of the consumers agreed to the statement that they find Magnum as outstanding in comparison to others.

\section{Question 2}

The second question in the survey inquired whether the Magnum ice cream is expensive in comparison to other brands. The response of the consumers showed a significant agreement where $23 \%$ consumers strongly agreed and $44 \%$ agreed to the statement which makes cumulative positive views of $67 \%$ whereas there were $28 \%$ neutral views and only $5 \%$ of consumers showed disagreement. The overall findings indicate that majority of the consumers believe that the Magnum ice cream is expensive since it is a differentiated product. This finding is in relation to the literature finding where Porter \& Heppelmann (2015) also argue that the differentiation is associated with a greater value and price because it has added value and features.

\section{Question 3}

The third question of the questionnaire was aimed to find whether Magnum offers an appropriate value for the price. The results obtained on this question revealed that that the majority of the cus- tomers agree that they find the price of Magnum appropriate for the quality and value offered. Particularly, there are $9 \%$ strongly agreed responses and $49 \%$ of agreed responses whereas a significant proportion of $31 \%$ also has neutral views. Nevertheless, only $11 \%$ of the responses were unfavorable. The findings reveal that the consumers agree to pay a higher price for the differentiated product like Magnum that is consistent with findings of (Gabrielsson et al., 2016) that consumers would pay a higher price for an added value.

\section{Question 4}

The fourth question of the questionnaire was aimed to inquire about the consumption of Magnum ice cream due to its rich quality and taste and the consumers agreed to the statement. Particularly, there were $17 \%$ of the respondents who strongly agreed and $48 \%$ agreed with the statement whereas a significant proportion of $30 \%$ had neutral views and $4 \%$ had disagreed and $1 \%$ strongly disagreed with the statement. Together, the results reveal that there are many aspects that the consumers consume Magnum ice cream apart from its rich quality and taste. It is also consistent with the finding of (D. Banker et al., 2014) that a differentiated product has value-added features and services that are also found in the results where consumers disagreed that they consume product only for taste and quality.

\section{Question 5}

The fifth question of the questionnaire survey inquired the respondents regarding the Omore brand of ice cream whether consumers believe it as an outstanding brand in the market. The findings revealed that $10 \%$ strongly agreed and $39 \%$ agreed with the statement whereas $38 \%$ had neutral views. Besides, there are $12 \%$ respondents who disagreed and $1 \%$ strongly disagreed. Nevertheless, the majority believed that Omore is an outstanding brand beside Magnum as reported by the consumers.

\section{Question 6}

The sixth question inquired from the respondents whether the Omore ice cream is expensive in comparison to the other brands available in the market. The results of the consumers reveal an unfavorable response where the majority of the respondents disagreed $22 \%$ and $2 \%$ strongly disagreed with the statement. There were only $8 \%$ 
respondents who agreed whereas $48 \%$ had neutral views. Conclusively, the findings revealed that consumers believe Omore as not an expensive brand and there are more expensive brands of ice cream in the market.

\section{Question 7}

This question of the survey inquired from the respondents regarding the value of Omore ice cream whether it is appropriate for the price that is offered by the company. In response, the majority of the consumers agreed with the statement that they find the price for the product justified for the value and quality delivered by the company where $9 \%$ strongly agreed, and $43 \%$ agreed whereas $41 \%$ had neutral views on the topic. On the other hand, there were only $6 \%$ respondents who disagreed, but none of the respondents strongly disagreed. To sum up, the findings indicated that consumers value the product because it is not highly priced and consider it fair value for the price.

\section{Question 8}

This question of the survey inquired from the respondents regarding the consumption of Omore ice cream whether they consume it because it is rich in quality and taste in comparison to others. However, the results relates to a study findings of Mathooko \& Ogutu, 2015 that there is added value into the product which differentiates it. Particularly, there were $55 \%$ respondents who agreed out of them $45 \%$ strongly agreed and $10 \%$ agreed. Only $8 \%$ disagreed with the statement.

\section{Question 9}

This question of the questionnaire inquired to measure the decision-making behavior of the consumers between the two prominent brands that include Walls Cornetto and Magnum against the price. The response of the consumers was indifferent where majority revealed that they would prefer Walls' Cornetto over Magnum as far as price is concerned. There results shows the response: $21 \%$ strongly agree, $43 \%$ agree, $23 \%$ neutral, $11 \%$ disagree, and $1 \%$ strongly disagree.

\section{Question 10}

This question was inquired to determine the preference of the consumers between Walls' Cornetto and Magnum when quality and taste are concerned. The findings were rather one-sided where $23 \%$ strongly agreed, and $46 \%$ agreed that they would prefer Magnum over Cornetto when taste and quality are concerned. These findings also reveal that differentiation created by the company is successful where the consumers believe that the taste and quality of the Magnum are higher than its counterparts.

\section{Question 11}

This question of the survey inquired from the respondents regarding the preference of ice cream brand between Omore and Cornetto against the price. There were variable responses of the consumers for this question where $16 \%$ strongly agreed, and $33 \%$ agreed whereas $15 \%$ disagreed and 5\% strongly disagreed and 30\% were neutral. These results reveal that the consumers can prefer any brand between Walls Cornetto and Omore as far as price is concerned and it also means that among consumers both the brands range between the similar price groups.

\section{Question 12}

The last question of the survey inquired the consumer's decision between Engro Foods brand Omore and Walls brand Cornetto as far as quality was concerned. The responses of the consumers were identical where $17 \%$ strongly agreed, and $34 \%$ agreed that they would prefer Omore over Cornetto as far as quality and taste are concerned. From these findings, it is also revealed that Omore is a differentiated product in comparison to Cornetto although it has similar price ranges. These are the reasons Omore is preferred by consumers over Cornetto.

To sum up the findings of the questionnaire survey, it can be said that the consumers prefer a differentiated product where the majority had selected Magnum when it was compared with Cornetto and selected Omore when it was compared with Cornetto. Nevertheless, the findings also were consistent with the literature that the consumers were attracted towards a differentiated product and preferred it (Mathooko \& Ogutu, 2015). When it comes to price, the consumers in the Pakistani market valued Cornetto because it has low price and when it comes to taste they have selected Magnum, and they have also considered rich in taste and quality among the other brands in the market. 


\subsection{Determining the impact of consumer's decision making towards differentiated strategy}

The findings from the analysis of the data obtained from the respondents through the survey were tested with SPSS and the regression results were drawn. The findings indicate a significant relationship between the two variables. Particularly, as indicated in Table 2 and 3 the analysis of variance is conducted for consumer's decision making and differentiated strategy of the company. The findings can be seen in the table that there is a significant value of differentiated strategy of the company and consumer's purchase decision that has a significant value below 0.05 in the Sig column that indicates value .000 . These results imply that there is a linear relationship between the two variables and the differentiated strategy of companies because it is preferred by the consumers. These results also indicated that the future predictions can be done on the basis of these values.

Table 2 Tess results for differientiation strategy

\begin{tabular}{|c|l|r|r|r|c|c|}
\hline \multicolumn{2}{|c|}{ Model } & $\begin{array}{c}\text { Sum of } \\
\text { Squares }\end{array}$ & df & $\begin{array}{c}\text { Mean } \\
\text { Square }\end{array}$ & F & Sig. \\
\hline \multirow{3}{*}{1} & Regression & 276.627 & 1 & 276.627 & 22.487 & $.000^{\mathrm{b}}$ \\
\cline { 2 - 7 } & Residual & 1205.563 & 98 & 12.302 & & \\
\cline { 2 - 7 } & Total & 1482.190 & 99 & & & \\
\hline
\end{tabular}

a. Dependent Variable: Likeness to brands

b. Predictors: (Constant), Differentiation strategy

Table 3 Coefficients ${ }^{a}$

\begin{tabular}{|c|l|r|r|c|}
\hline \multirow{2}{*}{ Model } & \multicolumn{2}{|c|}{$\begin{array}{c}\text { Unstandardized } \\
\text { Coefficients }\end{array}$} & $\begin{array}{c}\text { Standardized } \\
\text { Coefficients }\end{array}$ \\
\cline { 2 - 5 } \multicolumn{2}{|c|}{} & \multicolumn{1}{|c|}{ B } & Std. Error & Beta \\
\hline \multirow{3}{*}{1} & (Constant) & 14.260 & .949 & \\
\cline { 2 - 5 } & IV1 & .632 & .352 & .170 \\
\cline { 2 - 5 } & IV2 & 1.341 & .313 & .407 \\
\hline
\end{tabular}

a. Dependent Variable: Likeness

\subsection{Determining the impact of consumer's decision making towards low-cost strategy}

To know the low cost strategy of the companies there tests were conducted on two variables that were between consumer's decision making and low-cost leadership strategy of the company. Particularly, as indicated in Table 4 and 6 the analysis of regression test is conducted for consumer's decision making and low-cost leadership strategy of the company. The findings can be seen in the table that there is a significant value of low-cost leadership strategy of the company and con- sumer's purchase decision that has a significant value below 0.05 in the Sig column that indicates value .000 . These results imply that there is a linear relationship between the two variables and the differentiated strategy of Omore from Engro Foods has a significant value because it is preferred by the consumers.

Table 4 Test Results for Low Cost Strategy

\begin{tabular}{|l|r|r|r|c|c|}
\hline Model & $\begin{array}{r}\text { Sum of } \\
\text { Squares }\end{array}$ & df & $\begin{array}{c}\text { Mean } \\
\text { Square }\end{array}$ & $F$ & Sig. \\
\hline Regression & 365.879 & 2 & 182.940 & 15.896 & $.000^{\mathrm{b}}$ \\
1 Residual & 1116.311 & 97 & 11.508 & & \\
Total & 1482.190 & 99 & & & \\
\hline
\end{tabular}

a. Dependent Variable: Likeness to Brands

b. Predictors: Low-Cost strategy

Table 5 Coefficients $^{\mathrm{a}}$

\begin{tabular}{|c|l|r|r|c|}
\hline \multirow{2}{*}{ Model } & \multicolumn{2}{|c|}{$\begin{array}{c}\text { Unstandardized Co- } \\
\text { efficients }\end{array}$} & $\begin{array}{c}\text { Standardized } \\
\text { Coefficients }\end{array}$ \\
\cline { 2 - 5 } \multicolumn{2}{|c|}{} & \multicolumn{1}{|c|}{ B } & $\begin{array}{c}\text { Std. } \\
\text { Error }\end{array}$ & Beta \\
\hline \multirow{3}{*}{1} & (Constant) & 14.163 & 1.073 & \\
\cline { 2 - 5 } & IV3 & 0.614 & 0.347 & 0.163 \\
\cline { 2 - 5 } & IV4 & 1.414 & 0.331 & 0.394 \\
\hline \multicolumn{2}{|l}{} \\
\multicolumn{2}{|l}{ a. Dependent Variable: Likeness } \\
\hline
\end{tabular}

\subsection{Evaluating the successfulness of the differentiation strategy of competing companies}

The findings from the questionnaire survey revealed in the results from question 8 through 12 that the consumers prefer a differentiated brand Magnum and Omore over other brands in the market but when it comes to the price they also valued the product with lower price. In other words, the consumers in Pakistani market in the frozen dessert or ice cream sector do not only value differentiation, but they also value the price. Nevertheless, the successfulness of the differentiation strategy was realized when the consumers claimed that Magnum is expensive and they have also claimed that it is fair value for a price. Therefore, it can be claimed that the differentiation strategy is successful for Unilever Pakistan where the consumers prefer Magnum for its taste and quality that are its features.

Besides, the consumers also claimed that apart from these two features there are other factors that enable them to consume Magnum which is consistent with the study of (Gordon, 2013; Mathooko $\&$ Ogutu, 2015) that the products offer added 
value apart from being different. On the other hand, the consumers preferred Omore over Cornetto when they were compared price, quality, and taste. It also evidences that the consumers believe Magnum and Omore as a differentiated brand when it comes to quality and taste. Therefore, it can be said that the differentiation strategies of the competing companies are successful particularly of Unilever Pakistan for its Magnum brand that is highly valued by consumers. Notably, it was also found that Unilever Pakistan through its Cornetto brand also captures the Omore market that was illustrated and claimed that they would go for Cornetto; but the consumers preferred Magnum when it comes to taste and quality, which creates value for the consumers. In short, the findings evidence that differentiation strategy Unilever Pakistan for its Magnum is a success among Pakistani consumers in the frozen dessert market.

\section{Discussion, conclusion and recommendations}

\subsection{Discussion and conclusion}

The organizations in the contemporary business environment focus on creating differentiation strategies to outperform their competitors. In this essence, the purpose of the research was to analyze the differentiation strategies of the big companies that compete with each other. The undertaken companies were the big brands in the ice cream sector of Pakistani market that include Magnum and Walls from Unilever Pakistan and Omore from Engro Foods. The primary research was conducted using a survey questionnaire that was conducted by 100 consumers in Pakistan. The literature was also briefly discussed that identified the competing strategies of (Porter \& Heppelmann, 2014; Shani \& Chalasani, 1992) and it also identified that most of the companies compete with either differentiation or low-cost leadership. Besides, it was also found in the literature that the companies do not only achieve differentiation by creating value in the product, but they also add features to the product to create differentiation (Gabrielsson et al., 2016). Another finding was that the companies could achieve a sustainable competitive advantage over their counterparts when they create a product that is valuable, rare, difficult to imitate and organized by utilizing resources effectively.

The findings from the questionnaire survey revealed that the consumers in Pakistan do value the differentiation in products because they preferred
Magnum over Cornetto when it comes to taste and quality and they also believed that Magnum offers fair value for a price although it was found expensive among consumers. The research also evidences that there is a significant impact of consumer's decision making on differentiation strategy of the company and also the significant relationship between decision making and low-cost leadership was also found. In other research questions, it was also found that consumers not only prefer differentiated products but when it comes to price they prefer the product that offers good value at a low price that was illustrated in the decision of consumers where they preferred to purchase Omore over Cornetto believing it offers better value. Conclusively, the findings revealed that the differentiation strategy of Unilever Pakistan for its Magnum brand is a successful strategy because the company serves with differentiation with Magnum brand and for low-cost it serves with Cornetto brand.

\subsection{Recommendations}

This research was associated with a few limitations; therefore, it is essential to propose recommendation for further research. Firstly, the study was exploratory so it would have been suitable to conduct the mixed method research by collecting data in both the forms; however, due to time constraint it was not possible to conduct interviews from the consumers. Therefore, it is recommended to conduct a future research with mixed method approach and conducting interviews with the consumers to explore the consumer market of ice cream in Pakistan more effectively. 


\section{Appendices}

\section{Appendix A: Questionnaire survey}

This survey measures the behavior towards the company's competitive strategies for their frozen dessert or ice cream product. Kindly mark the boxes that best describe your thoughts and experiences for all questions.

\section{Preference of differentiated product (brand of Unilever Pakistan)}

1. I find Magnum ice cream as an outstanding product in comparison to other brands available in the market.

- Strongly agree

- Agree

- Neutral

- Disagree

- Strongly disagree

2. I find Magnum ice cream expensive in comparison to other brands available on the market.

- Strongly agree

- Agree

- Neutral

- Disagree

- Strongly disagree

3. I find quality and value of Magnum ice cream appropriate for the price offered by the company.

$$
\begin{aligned}
& \text { - } \text { Strongly agree } \\
& \text { - Agree } \\
& \text { - Neutral } \\
& \text { - Disagree } \\
& \text { - Strongly disagree }
\end{aligned}
$$

4. I consume Magnum ice cream because it is rich in quality and taste in comparison to other brands.

- Strongly agree

- Agree

- Neutral

- Disagree

- Strongly disagree

\section{Likeliness towards Differentiated Product (Brand of Engro Foods)}

5. I find Omore ice cream as an outstanding product in comparison to other brands available in the market.
- Strongly agree

- Agree

- Neutral

- Disagree

- Strongly disagree

6. I find Omore ice cream expensive in comparison to other brands available in the market.

- Strongly agree

- Agree

- Neutral

- Disagree

- Strongly disagree

7. I find quality and value of Omore ice cream appropriate for the price offered by the company.

- Strongly agree

- Agree

- Neutral

- Disagree

- Strongly disagree

8. I consume Omore ice cream because it is rich in quality and taste in comparison to other brands.

- Strongly agree

- Agree

- Neutral

- Disagree

- Strongly disagree

\section{Preference between a differentiated product and lower priced product}

9. I would prefer Magnum over Walls' Cornetto as far as price is concerned.

- Strongly agree

- Agree

- Neutral

- Disagree

- Strongly disagree

10. I would prefer Magnum over Walls' Cornetto as quality and taste are concerned.

- Strongly agree

- Agree

- Neutral

- Disagree

- Strongly disagree 
11. I would prefer Omore over Walls Cornetto as far as price is concerned.

- Strongly agree
- Agree
- Neutral
- Disagree
- Strongly Disagree

12. I would prefer Omore over Walls Cornetto as quality and taste are concerned.

- Strongly agree
- Agree
- Neutral
- Disagree
- Strongly disagree

\section{References}

Afridi, G. S., Saboor, A., Tariq, S. A. \& Ishaq, M. (2016). Exploring potential and opportunities for Pakistan's cotton export. Pakistan Journal of Agricultural Research, 29 (2) 188-201.

Anđelković, A. \& Radosavljević, M. (2018). Improving Order-picking Process Through Implementation of Warehouse Management System. Strategic Management International Journal of Strategic Management and Decision Support Systems in Strategic Management, 23 (1), 3-10.

Arli, D., Rundle-Thiele, S. \& Lasmono, H. (2015). Consumers' evaluation toward tobacco companies: implications for social marketing. Marketing Intelligence \& Planning, 33 (3), 276-291.

Armstrong, G., Kotler, P., Harker, M. \& Brennan, R. (2015). Marketing: an introduction: London: Pearson Education.

Beglari, S. (2017). Effective Competitive Strategies of US In Vitro Device Manufacturers. Washington: Walden University.

Block, J. H., Kohn, K., Miller, D. \& Ullrich, K. (2015). Necessity entrepreneurship and competitive strategy. Small Business Economics, 44 (1), 37-54.

Brenes, E. R., Montoya, D. \& Ciravegna, L. (2014). Differentiation strategies in emerging markets: The case of Latin American agribusinesses. Journal of Business Research, 67 (5), 847-855.

Brown, D. J. \& Fletcher, D. (2017). Effects of psychological and psychosocial interventions on sport performance: A meta-analysis. Sports Medicine, 47 (1), 77-99.

Cherrier, H. \& Gurrieri, L. (2014). Framing social marketing as a system of interaction: A neo-institutional approach to alcohol abstinence. Journal of Marketing Management, 30 (7-8), 607-633.

Corona, C., Saez, J. L. \& Stoffel, M. (2014). Defining optimal sample size, sampling design and thresholds for dendrogeomorphic landslide reconstructions. Quaternary Geochronology, 22, 72-84.

D. Banker, R., Mashruwala, R. \& Tripathy, A. (2014). Does a differentiation strategy lead to more sustainable financial performance than a cost leadership strategy? Management Decision, 52 (5), 872-896.
Davcik, N. S. \& Sharma, P. (2015). Impact of product differentiation, marketing investments and brand equity on pricing strategies: A brand level investigation. European Journal of Marketing, 49 (5/6), 760-781.

Farkas, F. (2016). Hard and Soft Approaches of Strategic Organisational Change Management. Strategic Management International Journal of Strategic Management and Decision Support Systems in Strategic Management, 21 (2), 13-22.

Ford, A., Moodie, C. \& Hastings, G. (2012). The role of packaging for consumer products: understanding the move towards 'plain'tobacco packaging. Addiction Research \& Theory, 20 (4), 339-347.

Gabrielsson, M., Seppälä, T. \& Gabrielsson, P. (2016). Realizing a hybrid competitive strategy and achieving superior financial performance while internationalizing in the high-technology market. Industrial Marketing Management, 54, 141-153.

Gallopel-Morvan, K., Gabriel, P., Le Gall-Ely, M., Rieunier, S. \& Urien, B. (2013). Plain packaging and public health: the case of tobacco. Journal of Business Research, 66 (1), 133-136.

Gellweiler, C. (2018). Cohesion of RBV and Industry View for Competitive Positioning. Strategic Management International Journal of Strategic Management and Decision Support Systems in Strategic Management, 23 (2) 3-12.

Gilmore, A. B., Tavakoly, B., Taylor, G. \& Reed, H. (2013). Understanding tobacco industry pricing strategy and whether it undermines tobacco tax policy: the example of the UK cigarette market. Addiction, 108 (7), 13171326.

Gordon, R. (2013). Unlocking the potential of upstream social marketing. European Journal of Marketing, 47 (9), 1525-1547.

Grant, R. M. (2016). Contemporary strategy analysis: Text and cases edition: Oxford: John Wiley \& Sons.

Greenland, S. J. (2013). Cigarette brand variant portfolio strategy and the use of colour in a darkening market. Tobacco Control, Hawthorn, Victoria, Australia24(e1), e65-e71. doi:10.1136/tobaccocontrol-2013-051055

Greenland, S. J. (2016). The Australian experience following plain packaging: the impact on tobacco branding. Addiction, 111 (12), 2248-2258.

Hansen, E., Nybakk, E. \& Panwar, R. (2015). Pure versus hybrid competitive strategies in the forest sector: Performance implications. Forest Policy and Economics, 54, 51-57.

Hartley, J. (2014). Some thoughts on Likert-type scales. International Journal of Clinical and Health Psychology, 14 (1), 83-86.

Heale, R. \& Twycross, A. (2015). Validity and reliability in quantitative studies. Evidence-based nursing, 18(3), 66-67. doi:10.1136/eb-2015-102129

Henriksen, L. (2012). Comprehensive tobacco marketing restrictions: promotion, packaging, price and place. Tobacco control, 21 (2), 147-153.

Hoek, J. \& Robertson, C. (2015). How do young adult female smokers interpret dissuasive cigarette sticks? A qualitative analysis. Journal of Social Marketing, 5 (1), 21-39.

Hsu, R., Myers, A. E., Ribisl, K. M., \& Marteau, T. M. (2013). An observational study of retail availability and in-store marketing of e-cigarettes in London: potential to undermine recent tobacco control gains? BMJ Open, 3(12), e004085. doi:10.1136/bmjopen-2013-004085 
Huang, J. L., Liu, M., \& Bowling, N. A. (2015). Insufficient effort responding: Examining an insidious confound in survey data. Journal of Applied Psychology, 100(3), 828-845. doi:10.1037/a0038510

Hudson, S., Huang, L., Roth, M. S. \& Madden, T. J. (2016) The influence of social media interactions on consumer-brand relationships: A three-country study of brand perceptions and marketing behaviors. International Journal of Research in Marketing, 33 (1), $27-41$

Joshi, A., Kale, S., Chandel, S. \& Pal, D. (2015). Likert scale: Explored and explained. British Journal of Applied Science \& Technology, 7 (4), 396-403.

Kilian, T. \& Hennigs, N. (2014). Corporate social responsibility and environmental reporting in controversial industries. European Business Review, 26 (1), 79-101.

Kim, N., Shin, S. \& Min, S. (2016). Strategic marketing capability: Mobilizing technological resources for new product advantage. Journal of Business Research, 69 (12), 5644-5652.

Koulayev, S. (2014). Search for differentiated products: identification and estimation. The RAND Journal of Economics, 45 (3), 553-575.

Laari, S., Töyli, J. \& Ojala, L. (2017). Supply chain perspective on competitive strategies and green supply chain management strategies. Journal of Cleaner Production, 141, 1303-1315.

Lechner, C. \& Gudmundsson, S. V. (2014). Entrepreneurial orientation, firm strategy and small firm performance. International Small Business Journal, 32 (1), 36-60.

Lee, J. G., Henriksen, L., Rose, S. W., Moreland-Russell, S. \& Ribisl, K. M. (2015). A systematic review of neighborhood disparities in point-of-sale tobacco marketing. American journal of public health, 105 (9), e8-e18.

Lewis, M. J., \& Ling, P. M. (2015). "Gone are the days of mass-media marketing plans and short term customer relationships": tobacco industry direct mail and database marketing strategies. Tobacco Control, 25(4), 430-436. doi:10.1136/tobaccocontrol-2015-052314

Liu, W., \& Atuahene-Gima, K. (2018). Enhancing product innovation performance in a dysfunctional competitive environment: The roles of competitive strategies and market-based assets. Industrial Marketing Management, 73, 7-20. doi:https://doi.org/10.1016/j.indmarman.2018.01.006

Loken, B. A. R. B. A. R. A., Viswanath, K., Wakefield, M., Batra, R., Keller, P. A., \& Strecher, V. J. (2011). Controlling obesity: Lessons learned from tobacco control and tobacco marketing research (pp. 359-71). Armonk, NY: ME Sharpe.

Lotterhos, K. E. \& Whitlock, M. C. (2015). The relative power of genome scans to detect local adaptation depends on sampling design and statistical method. Molecular ecology, 24(5), 1031-1046.

Manev, I. M., Manolova, T. S., Harkins, J. A. \& Gyoshev, B. S. (2015). Are pure or hybrid strategies right for new ventures in transition economies? International Small Business Journal, 33 (8), 951-973.

Mathooko, F. M. \& Ogutu, M. (2015). Porter's five competitive forces framework and other factors that influence the choice of response strategies adopted by public universities in Kenya. International Journal of Educational Management, 29 (3), 334-354.
McAuley, A. (2014). Reflections on a decade in social marketing. Journal of Social Marketing, 4 (1), 77-86.

Oyewobi, L. O., Windapo, A. O. \& James, R. O. B. (2015). An empirical analysis of construction organisations competitive strategies and performance. Built Environment Project and Asset Management, 5 (4), 417-431.

Porter, M. E. \& Heppelmann, J. E. (2014). How smart, connected products are transforming competition. Harvard Business Review, 92 (11), 64-88.

Porter, M. E. \& Heppelmann, J. E. (2015). How smart, connected products are transforming companies. Harvard Business Review, 93 (10), 96-114.

Porter, M. E. \& Lee, T. H. (2015). Why strategy matters now. New England Journal of Medicine, 372 (18), 16811684.

Rothaermel, F. T. (2015). Strategic management New York City, NY: McGraw-Hill Education.

Rungtrakulchai, R. (2018). The relationship between price deals, perceived quality, and brand equity for a high involvement product. AU Journal of Management, 11 (2), 36-45.

Sacks, G., Mialon, M., Vandevijvere, S., Trevena, H., Snowdon, W., Crino, M. \& Swinburn, B. (2015). Comparison of food industry policies and commitments on marketing to children and product (re) formulation in Australia, New Zealand and Fiji. Critical Public Health, 25 (3), 299-319.

Salavou, H. E. (2015). Competitive strategies and their shift to the future. European Business Review, 27 (1), 80-99.

Schmidt, F. L. \& Hunter, J. E. (2014). Methods of metaanalysis: Correcting error and bias in research findings: London Sage publications.

Shani, D. \& Chalasani, S. (1992). Exploiting niches using relationship marketing. Journal of consumer marketing, 9 (3), 33-42.

Sharma, S. \& Sharma, P. (2017). Marketing Mix Strategies for FMCG Companies in India. Journal of Commerce and Management Thought, 8 (4), 760-771.

Sparks, R. E. (2015). 11.2 the Olympics and the marketing of sports: Special issues in sponsorship. Paper presented at the Proceedings of the 1995 World Marketing Congress.

Stead, M., Moodie, C., Angus, K., Bauld, L., McNeill, A., Thomas, J., . . Kwan, I. (2013). Is consumer response to plain/standardised tobacco packaging consistent with framework convention on tobacco control guidelines? A systematic review of quantitative studies. PloS one, 8 (10), 1-10, e75919. doi:10.1371/journal.pone.0075919

Tan, Q. \& Sousa, C. M. (2015). Leveraging marketing capabilities into competitive advantage and export performance. International Marketing Review, 32 (1), 78-102.

Taylor, S. J., Bogdan, R. \& DeVault, M. (2015). Introduction to qualitative research methods: A guidebook and resource Hoboken, New Jersey, USA: John Wiley \& Sons.

Voss, S., Zimmermann, B. \& Zimmermann, A. (2016). Detecting spatial structures in throughfall data: the effect of extent, sample size, sampling design, and variogram estimation method. Journal of Hydrology, 540, 527-537.

Walsh, G., Shiu, E. \& Hassan, L. M. (2014). Cross-national advertising and behavioral intentions: A multilevel analysis. Journal of International Marketing, 22 (1), $77-$ 98 
Xie, Y. \& Lu, P. (2015). The sampling design of the China family panel studies (CFPS). Chinese Journal of Sociology, 1 (4), 471-484.

Zdraveski, D., Janeska, M. \& Taleska, S. (2014). UML model of business intelligence system in increasing corporate performance. Strategic Management

\section{$\triangle$ Correspondence}

\section{Ze Ye, Hassan Abbas}

1 Affiliation Changsha University of Science \& Technology 410004, Changsha, China

E-mail: hassanabbas@csust.edu.cn hassan_smart55@yahoo.com
International Journal of strategic management and decision support systems in strategic management, 19 (1) 22-27. 